\title{
Leveraging High-Quality Research to Define the Gastric Cancer Landscape in India
}

\author{
Shaila J. Merchant ${ }^{1,2} \cdot$ Chandramohan Krishnan Nair ${ }^{3} \cdot$ Christopher M. Booth $^{2,4}$ \\ Published online: 19 April 2020 \\ (C) Indian Association of Surgical Oncology 2020
}

Cancer is the second leading cause of death globally [1]; unfortunately, patients in low- and middle-income countries have poorer outcomes compared with those observed in high-income countries [2]. In India, a low middle-income country, the number of new cases and deaths due to cancer has been rising [3] and is expected to nearly double to 1.7 million cases by 2035 [4]. Within this statistic, gastric cancer remains an interesting area of study. Although a substantial reduction in the age-standardized incidence rate has been observed, there remains tremendous variation in incidence rates across the states of India with incidence in some states being ranked among those in well-known high incidence countries such as China and Chile [5]; furthermore, gastric cancer was responsible for the highest proportion of cancer disabilityassociated life-years in the country [3].

The incidence of and death from gastric cancer in India differ based on geographic region. Some of the highest death rates from gastric cancer are observed in states such as Mizoram, Uttar Pradesh, Uttarakhand, Sikkim, Telangana, Andhra Pradesh, and Goa [3]. These states are in the northern, eastern, and southern regions of India. Interestingly, there is relative sparing of other states such as Gujarat, Delhi, Maharashtra, and Punjab [3]. The regional variation is thought to be related to differences in genetic and environmental factors [6]. The multifactorial and complex nature of this problem

Shaila J. Merchant

shaila.merchant@kingstonhsc.ca

1 Division of General Surgery and Surgical Oncology, Queen's University, Kingston, Ontario, Canada

2 Cancer Care and Epidemiology, Queen's Cancer Research Institute, Kingston, Ontario, Canada

3 Division of Surgical Oncology, Regional Cancer Centre, Trivandrum, Kerala, India

4 Division of Medical Oncology, Queen's University, Kingston, Ontario, Canada makes it difficult to pinpoint the exact contributions of individual risk factors.

Literature related to gastric cancer outcomes in India remains sparse, with existing outcomes-based literature limited to single-center experiences. In a publication from Sambasivaiah et al. [7], patients with gastric cancer in Andhra Pradesh (southern India) were more likely to be male, have adenocarcinoma and distally located cancers, and present with advanced, incurable disease. Survival was poor in this cohort at 10 months. In Manipur, a state in north-eastern India, Barad et al. [8] reported male-, adenocarcinoma-, and antrumpredominance in patients with gastric cancer. In this cohort, advanced disease was common, with $37 \%$ of patients presenting with metastatic disease. Dietary factors were implicated in a crude way based on patient reports of consumption of smoked meat and fermented fish. Reviews on epidemiology and treatment of gastric cancer in India have been performed but are limited [6,9-11]. With respect to epidemiology, implicated risk factors include infection from Helicobacter pylori with a high prevalence in India [12], dietary factors such as high consumption of salty, spicy, and fermented foods in certain states, tobacco and alcohol, and genetic susceptibility, with a myriad of genetic polymorphisms conferring more or less risk to the development of gastric cancer [9].

With respect to treatment of gastric cancer in India, little is published. Details on staging, multimodality approach including selective use of radiotherapy and chemotherapy, and surgical methodology are sparse in these publications [10, 11, 13]. The Indian Council of Medical Research [14, 15] and the National Cancer Grid [16] have published consensus documents and guidelines, respectively, on the management of gastric cancer. The principles of management are in keeping with principles outlined by other major societies such as the National Comprehensive Cancer Network and the European Society of Medical Oncology. Despite the presence of such management guidelines, there are significant gaps in knowledge regarding actual outcomes related to gastric cancer in India. 
There are many unanswered questions. How are the various states in India approaching gastric cancer? What are the patient outcomes? What are the challenges to providing patients with the best care? How can we best address these knowledge gaps? We propose investment in research as a first step to gaining insight into some of these questions. Sound, sustainable clinical research will require the support of key stakeholders in terms of manpower, time, infrastructure, and financial resources. Training of personnel in India in research methods is imperative for any research program to remain sustainable. Appropriate collaborations with experts in other countries may enhance the quality of the research. The research network must have diverse representation from those involved in all aspects of gastric cancer care including primary health care, nursing, dietetics, medical, radiation and surgical oncologists, pathologists, radiologists, and those in basic and clinical research and must include representatives from all states in India.

Our group is interested in defining the current status of gastric cancer care in India through significant investments in research. Our proposed agenda includes the following objectives:

1. Development of a multidisciplinary gastric cancer research network in India. This will involve engaging high-volume tertiary care centers, using existing cancer registries and establishing new registries in areas that do not have any. Leaders from each state in India will need to play a role in this initiative, thus increasing collaborative capacities. Personnel will need to be trained in using registry information to conduct outcomes research. Research infrastructure will need to be created and supported. This information will be used to gain a better understanding of current outcomes and could eventually be used to compare information from Indian patients to others globally.

2. Development of collaborative relationships with countries that are leaders in gastric cancer research. Our group represents a partnership between India and Canada; however, we plan to engage other research leaders from around the world to enhance the quality and applicability of the research. The Indian population is likely under-represented in gastric cancer trials, a problem which may be addressed, in part, by improving collaborative relationships with countries that lead such trials.

3. Development of collaborative relationships with countries that are leaders in the clinical management of gastric cancer. This will require a better understanding of where and how gastric cancer is treated in India. If deficiencies are identified, then they could be addressed by appropriate training conducted by clinicians from other countries or creating opportunities for Indian clinicians to learn abroad. Similarly, the reasonably high volumes of gastric cancer in specific Indian states may offer opportunities for countries with lower volumes to learn from Indian clinicians.

4. Development of initiatives that may lead to earlier detection of gastric cancer. This will require a better understanding of whether early-detection initiatives currently exist. Consideration could be given to screening programs (usually with endoscopy) in particularly high-risk populations in India as well as increased primary provider education regarding signs and symptoms of gastric cancer.

5. Understanding barriers to implementation of the abovementioned objectives. Many cultural, socioeconomic, demographic, educational, and financial factors will be barriers to our objectives. A better understanding of these factors will require ground-level research before any initiatives are put into action. Anticipated barriers include cultural differences and readiness to accept treatment if available, socioeconomic disparities, access to appropriate healthcare, lack of appropriately trained research personnel, lack of research infrastructure, lack of adequately trained providers, and lack of financial resources to support costs of screening programs, treatment, and research.

The abovementioned objectives have been recognized as areas of deficiency in India [17]. Gastric cancer contributes significantly to the overall cancer burden in India, but little is known about patient outcomes at this time. The time has come to improve research capacity and to use this to better understand the current gastric cancer landscape India.

\section{Compliance with Ethical Standards}

Conflict of Interest The authors declare that they have no conflict of interest.

\section{References}

1. Global Burden of Disease Cancer C, Fitzmaurice C, Akinyemiju TF, Al Lami FH, Alam T, Alizadeh-Navaei R et al (2018) Global, regional, and national cancer incidence, mortality, years of life lost, years lived with disability, and disability-adjusted life-years for 29 cancer groups, 1990 to 2016: a systematic analysis for the Global Burden of Disease Study. JAMA Oncol 4(11):1553-1568

2. Chalkidou K, Marquez P, Dhillon PK, Teerawattananon Y, Anothaisintawee T, Gadelha CA et al (2014) Evidence-informed frameworks for cost-effective cancer care and prevention in low, middle, and high-income countries. Lancet Oncol 15(3):e119-e131

3. The burden of cancers and their variations across the states of India: the Global Burden of Disease Study 1990-2016. The Lancet Oncology. 2018;19(10):1289-306

4. Mallath MK, Taylor DG, Badwe RA, Rath GK, Shanta V, Pramesh CS, Digumarti R, Sebastian P, Borthakur BB, Kalwar A, Kapoor S, Kumar S, Gill JL, Kuriakose MA, Malhotra H, Sharma SC, Shukla S, Viswanath L, Chacko RT, Pautu JL, Reddy KS, Sharma KS, Purushotham AD, Sullivan R (2014) The growing burden of cancer 
in India: epidemiology and social context. Lancet Oncol 15(6): e205-e212

5. National Centre for Disease Informatics and Research, National Cancer Registry Programme. Three year report of populationbased cancer registries, 2012-2014.: Indian Council of Medical Research [cited 2020 January 22]. Available from: http:// ncdirindia.org/NCRP/ALL_NCRP_REPORTS/PBCR_REPORT 2012 2014/ALL CONTENTT/Printed Version.htm

6. Sharma A, Radhakrishnan V (2011) Gastric cancer in India. Indian J Med Paediatr Oncol 32(1):12-16

7. Sambasivaiah K, Ibrarullah M, Reddy MK, Reddy PV, Wagholikar G, Jaiman S, Reddy DG, Sarma KV, Hegde GN (2004) Clinical profile of carcinoma stomach at a tertiary care hospital in South India. Trop Gastroenterol 25(1):21-26

8. Barad AK, Mandal SK, Harsha HS, Sharma BM, Singh TS (2014) Gastric cancer-a clinicopathological study in a tertiary care centre of North-eastern India. J Gastrointest Oncol 5(2):142-147

9. Dikshit RP, Mathur G, Mhatre S, Yeole BB (2011) Epidemiological review of gastric cancer in India. Indian J Med Paediatr Oncol 32(1):3-11

10. Ibrahim M, Gilbert K (2017) Management of gastric cancer in Indian population. Transl Gastroenterol Hepatol 2:64

11. Servarayan Murugesan C, Manickavasagam K, Chandramohan A, Jebaraj A, Jameel ARA, Jain MS, Venkataraman J (2018) Gastric cancer in India: epidemiology and standard of treatment. Updat Surg 70(2):233-239

12. Misra V, Pandey R, Misra SP, Dwivedi M (2014) Helicobacter pylori and gastric cancer: Indian enigma. World J Gastroenterol 20(6):1503-1509
13. Shrikhande SV, Shukla PJ, Qureshi S, Siddachari R, Upasani V, Ramadwar M, Kakade AC, Hawaldar R (2006) D2 lymphadenectomy for gastric cancer in Tata Memorial Hospital: Indian data can now be incorporated in future international trials. Dig Surg 23(3): 192-197

14. Shrikhande SV, Sirohi B, Barreto SG, Chacko RT, Parikh PM, Pautu J, Arya S, Patil P, Chilukuri SC, Ganesh B, Kaur T, Shukla D, Rath GS (2014) Indian Council of Medical Research consensus document for the management of gastric cancer. Indian J Med Paediatr Oncol 35(4):239-243

15. Indian Council of Medical Research (2014) Consensus document for management of gastric cancer New Delhi

16. National Cancer Grid. Stomach and Gastroesophageal Cancer (Adenocarcinoma) [cited 2020 January 15]. Available from: https://tmc.gov.in/NCG/DOCS/pdf/Gastrointestinal/Stomach \&_Gastroesophageal_JunctionCancer.pdf

17. Sullivan R, Badwe RA, Rath GK, Pramesh CS, Shanta V, Digumarti R, D'Cruz A, Sharma SC, Viswanath L, Shet A, Vijayakumar M, Lewison G, Chandy M, Kulkarni P, Bardia MR, Kumar S, Sarin R, Sebastian P, Dhillon PK, Rajaraman P, Trimble EL, Aggarwal A, Vijaykumar DK, Purushotham AD (2014) Cancer research in India: national priorities, global results. Lancet Oncol 15(6):e213-e222

Publisher's Note Springer Nature remains neutral with regard to jurisdictional claims in published maps and institutional affiliations. 